\title{
O discurso médico e a Educação Física nas escolas (Brasil, século XIX)
}

CDD. 20.ed. 796.017

796.0981

http://dx.doi.org/10.1590/1807-55092014000200273
Luciene Henrique da COSTA*

Marysol de Souza SANTOS* Edivaldo GÓIS JUNIOR ${ }^{* *}$

\section{Resumo}

Para os médicos, a reforma da sociedade não residia apenas nas ruas, nas avenidas, nas construções, enfim, em uma urbanização com base em preceitos da saúde. Era impreterível incutir uma reforma dos corpos, que ocorria primeiro no núcleo familiar através da educação higiênica na infância. É neste campo específico da Higiene que os exercícios físicos tornaram-se foco de interesse dos médicos. 0 objetivo deste estudo é descrever o contexto de escolarização da Educação Física mediante o discurso médico do século XIX. Para isto, realizou-se uma pesquisa histórica e documental que teve como fontes: as teses para a obtenção do título de doutor da Faculdade de Medicina do Rio de Janeiro e Bahia. Conclui-se que a mentalidade higienista colaborou para a lenta difusão dos exercícios físicos no contexto educacional do século XIX. Contudo a relevância da ginástica era secundária no projeto higienista.

Palavras-chave: História da medicina; Educação física escolar; Higiene; Corpo.

\section{Introdução}

Durante todo o século XIX, principalmente a partir da criação das faculdades de Medicina no Rio de Janeiro e na Bahia, em 1808, cresce a consciência sobre a insalubridade das cidades, o controle das doenças, e a necessidade de organização pública de um sistema de atenção à saúde. Não que isto se traduzisse em açôes afirmativas, em estratégias e políticas governamentais que possibilitassem uma intervenção no que diz respeito à saúde coletiva e individual, mas sim, na idealização destas proposiçóes.

Era no campo da medicina e no debate intelectual que a saúde ganhava espaço, o que proporcionou durante o século XIX iniciativas isoladas que não abrangiam a maior parte da populaçáo brasileira, e quando muito, afetavam a capital da corte, o Rio de Janeiro. Afastando desta maneira, paulatinamente, um Brasil rural daquele que se constituía no Rio de Janeiro, que guardando suas diferenças, tentava cada vez mais aproximar-se de uma representação europeia de cidade.

As epidemias, as febres, os focos de infecção e contágio do ar e da água sempre foram fantasmas para a administração colonial. Com a chegada da família real, a situação começou a mudar. A pressão populacional e as exigências higiênicas da nova camada urbana aceleraram as necessidades de modernização. A medicina passou a ser solicitada mais insistentemente. E, pelo fato de possuir métodos, objetivos e técnicas mais aprimoradas supriu inicialmente a inoperância da burocracia governamental ${ }^{1}$.

Porém as efetivas mudanças só ocorrem no final do século XIX e início do século XX. Período em que a insalubridade da cidade ainda merecia destaque, sobretudo, pela prevalência de diversas doenças. Para o historiador Nicolau SeVCENKO²:

[...] A cidade era foco endêmico de uma infinidade de moléstias: febre amarela, febre tifóide, impaludismo, varíola, peste bubônica, tuberculose, entre outras. [...] Por isso, as tripulaçōes e passageiros nem se atreviam a descer dos navios quando estes chegavam ao porto: permaneciam a uma distância prudente, para evitar contágio (p.63).

Desse modo, além da urgência em aplicar os preceitos higiênicos na época, o higienismo do século XIX teve consequências de longo prazo em termos de políticas públicas e na constituição de um corpo de profissionais atrelado ao ideário da saúde. Seus
*Escola de Educação Física e Desportos Universidade Federal do Rio de Janeiro.

*Faculdade de Educação Física, Universidade Estadual de Campinas. 
diagnósticos e argumentos ajudaram a legitimar a presença do Estado no campo da saúde pública ${ }^{3-4}$, mas também no campo educacional.

Do ponto de vista médico, não eram apenas as cidades que mereciam uma pertinente transformação. A reforma dos hábitos não residia apenas nas ruas, nas avenidas, nas construçóes, enfim, em uma urbanização com base em preceitos da saúde. Era impreterível, para

\section{Método}

Em termos metodológicos, realizou-se uma pesquisa histórica e documental que teve como fontes: as teses para a obtenção do título de doutor da Faculdade de Medicina do Rio de Janeiro e Bahia. O critério de seleçáo dos documentos obedeceu à temática central da educação física relacionada à higiene. Os documentos foram delimitados também por uma periodização definida pelo século XIX. Os dados foram coletados nos acervos da Biblioteca do Centro de Ciências da Saúde da Universidade Federal do Rio de Janeiro (UFRJ) e da Faculdade de Medicina da Bahia.

No acervo baiano, no período de 1840 a 1900, correspondente ao início da exigência da escrita de uma tese para conclusáo de curso até o fim da periodização deste estudo, tivemos como critério de inclusão na amostra, a seleção de documentos que foram catalogados com os termos "collegios", "escholar", "hygiene escholar"; "educação physica", "gymnastica". O resultado foi de cinco teses.

No acervo da Faculdade de Medicina do Rio de Janeiro, na periodização de 1833 a 1900, a partir do "Catálogo de Teses da Faculdade de Medicina"', aplicados os mesmos procedimentos de pesquisa foram encontradas três teses.

Para a análise dos dados empíricos, caracterizados pelos documentos encontrados, adotamos a perspectiva teórica da história cultural com o enfoque na história das mentalidades 7 . Para Ariès ${ }^{8}$ a difícil ideia de mentalidade pode ser assim explicada:

Certas coisas, portanto, eram concebíveis, aceitáveis, em determinada época, em determinada

\section{Resultados e discussão}

Durante o século XIX, teve origem no Rio de Janeiro e na Bahia, a mobilização de médicos, intelectuais e políticos em torno de projetos que aquele discurso, a reforma dos corpos, que para Jacques DONZELOT $^{5}$ ocorria primeiro no núcleo familiar através da inculcaçáo de hábitos higiênicos nas crianças.

É neste campo específico da higiene que os exercícios físicos tornaram-se foco de interesse por parte dos médicos. O objetivo deste estudo é descrever o contexto de escolarização da Educaçáo Física mediante o discurso médico do século XIX.

cultura, e deixam de sê-lo em outra época e numa outra cultura. $\mathrm{O}$ fato de não podermos mais nos comportar hoje com a mesma boa-fé [...], indica precisamente que interveio entre elas e nós a uma mudança de mentalidade (p.207).

Desse modo, entender a mentalidade dos médicos higienistas em seu contexto, com suas contrariedades, especificidades, é relacionar-se com uma época específica que tinha como objetivo problematizar a sociedade brasileira. Desse modo, nossos dados empíricos não sustentam a construção de uma explicação puramente estruturante que seja reproduzida em diversos contextos, pois limita-se a perceber as especificidades de dada sociedade, em determinado tempo. "A diferença torna-se entáo a condiçáo da particularidade, e da inteligência da particularidade: ela separa essa cultura da nossa e assegura-lhe uma originalidade" $^{8}$ (p.231). Além disso, na análise do "corpus" documental, ou seja, na totalidade dos escritos das teses, não tivemos a pretensão de se apropriar de suas mentalidades como uma representaçáo verdadeira do Brasil, pois elas não são suficientes para explicar a sociedade brasileira do período. Mas sim, desejamos simplesmente descrever as especificidades do discurso médico perante as demandas sociais brasileiras, em específico, as educacionais. Esse exercício nos leva a identificar uma mentalidade, que a chamamos de higienista. A partir dela construímos uma narrativa que descreve seus discursos, tão somente para designar o que era dito pelos médicos no âmbito do que chamavam de "educação physica".

propiciaram o avanço do processo da institucionalização da medicina ${ }^{9}$. Assim o discurso médico foi elaborado sobre um modelo de ciência que se 
constituiu historicamente e se fez presente através de um conjunto de propostas que se referiram à saúde coletiva e individual ${ }^{10-13}$.

Naquele cenário, os médicos pontuavam alguns fatores desfavoráveis que explicavam a falta de saúde dos brasileiros. Como, por exemplo, as desigualdades econômicas; as precárias condições habitacionais; o alcoolismo; a má alimentação; a falta de exposição à luz solar; e o corpo fraco por falta de exercício físico.

Desse modo, os médicos destacavam o papel da ciência, da sociedade civil e do Estado na higienização dos corpos, incutindo concepçóes, valores e hábitos que tinham um papel significativo na construção e na ordenação da racionalidade social ${ }^{11}$.

A medicina do século XIX descrevia a sociedade brasileira como um "lócus" onde se convivia mediante um pêndulo no qual se marcava o certo e o errado, bem como os meios que conduziriam a um e a outro. Os higienistas dividiam-se nas estratégias, que incidiam, contudo, em objetivos semelhantes: produzir sujeitos higiênicos, higienizados e higienizadores ${ }^{14}$.

Com todos os problemas sociais que o Brasil enfrentava na época, a intervenção higiênica foi valorizada como o remédio não só para as condiçôes de vida, mas também como força motriz de uma mudança de hábitos e mentalidades que se traduziam nos corpos. Desse modo, a higiene, como ramo da medicina, olhou para várias instituiçôes da sociedade, e principalmente, para a Escola.

Por isso, a escola também era objeto das teses médicas, como no caso da tese do Dr. Francisco Candido da Silva Lово $^{15}$, defendida em 1895, intitulava-se "Apontamentos para o estudo da higyene escholar", onde ressalta a importância da Escola na instrução e na educação higiênica com o intuito de preparar a criança para a sociedade.

A educação então era vista como um caminho para fazer com que os hábitos higiênicos se multiplicassem. Para GONDRA ${ }^{16}$ esta tentativa de disseminar o pensamento higienista nas escolas, residia no fato de que a formação intelectual, moral e física da juventude baseava-se em um conjunto de medidas orientadoras, que por sua vez, tinha sua origem na doutrina mais ampla do pensamento higienista, preocupado em estruturar, edificar e controlar o funcionamento dos colégios, intervindo, dessa maneira, em uma educaçấo dos corpos e, por conseguinte, na própria construção do futuro do país.

A mentalidade higienista no campo da educaçáo articulava-se ao discurso de identidade nacional. Por exemplo, o Dr. José Lopes Patury ${ }^{17}$, em sua tese
"Hygiene Escholar" de 1884, enfatiza sua preocupação com a escolarização, relatando que: "as crianças que, mais tarde cidadáos, serão a força material d'uma nação, sua esperança e seu apoio" (p.3). O Dr. Francisco Candido da Silva Loвo ${ }^{15}$ também é enfático: "preparar a geração que surge para com patriotismo corrigir os erros do presente" (p.1).

Além disso, o aumento do prestígio que a medicina estava vivendo durante os anos oitocentistas consolidou a higiene como centro da ciência médica e âncora dos seus projetos ${ }^{12}$.

Esta contextualização favoreceu a institucionalização de novas práticas corporais, como a "gymnastica", que orientadas mediantes regulaçóes e orientações, produziram as demandas necessárias para a organização, em específico, de uma ocupação, qual seja a de mestres de "gymnastica". Assim na gênese do que hoje chamamos de Educação Física, aqueles sujeitos históricos envolvidos nestas práticas viram neste movimento uma oportunidade para sua afirmação. Em 1863, o Dr. Wilhelm NAegeli ${ }^{18}$, em sua tese "A utilidade dos exercícios gymnasticos nos paizes tropicaes", defendeu os exercícios como hábito cotidiano, revelando que o clima quente era um empecilho para a disseminação desta prática corporal que deveria ser desmitificado no contexto brasileiro. Fato que indicia que o pensamento médico construía argumentos para a legitimação da prática. O Dr. Wilhelm NAEGeli ${ }^{18}$ disserta:

Depois de examinarmos assim o nosso problema, declaramos os exercícios gymnasticos nos paizes trópicos, não sómente não prejudiciaes, mas ao contrario bem uteis. Com tratamento razoavel, elles são o melhor modo de corrigir aquellas influencias debilitantes do clima dos tropicos, e principalmente para aquela parte da população, cuja occupação mais intellectual reduz muito os movimentos do corpo, elles tornam-se uma necessidade. Para esta parte da população, e principalmente para juventude, os exercicios gymnasticos são um beneficio que se manifesta não só em saude e força, como tambem em energia e vigor do espirito. Nenhum clima dá o privilegio da indolencia á seus habitantes, embora um clima temperado favoreça mais a actividade e o desenvolvimento das qualidades varouis. Nos lugares onde o homem tem de lutar com muitas difficuldades para obter do solo o que elle precisa, não há necessidade de procurar occasiões para a actividade, mas mesmo lá, onde a natureza lhe forneceu tudo prodigamente, aonde o homem colhe sem ter semeado, mesmo nestes paizes o 
homem tem outra missão, que não é sómente gozar e desfructar. Se as necessidades da vida não o obrigam ao trabalho, elle é forçado por influencias externas ou pela sua tendencia a procurar aquella saude e vigor do corpo, e do animo pelas quaes só a vida tem atractivos (p.14).

No século XIX, os "exercícios gymnasticos" faziam parte de um conjunto de hábitos higiênicos identificados no âmbito de um termo mais amplo denominado "educação physica". Desse modo, os exercícios físicos correspondiam apenas a um aspecto específico. Em uma das primeiras teses sobre o assunto no Brasil, em 1846, pelo médico mineiro Dr. Joaquim Pedro de Mello ${ }^{19}$, intitulada "Generalidades acerca da educação physica dos meninos", o termo era polissêmico. Em seus termos:

Os authores que hão publicado obras á cerca desta ultima parte da educação, de que unicamente tencionamos tractar, divergem todos relativamente â denominação, que mais adequadamente lhes compete. Uns, com Mr. Des-essartz, a appellidão educação corporea. Outros, como Mr. Raulin, a charnão arte da conservação dos meninos. Brouzet, da-lhe o nome de educação medicinal. Alguns, seguindo a opinião do erudito, e celebre author d'Emilio, a intitulão educação natural. E, finalmente, Mr. Ballexserd, de Gênova, em sua dissertação, apresentada em 1761 á academia de Harlem, a designou por educação physica (p.III).

Percebe-se nos escritos que o debate que envolvia o termo "educação physica" era heterogêneo. Essa amplitude, com um termo táo largo, possibilitou a discussão de muitos aspectos da vida, do nascimento à vida adulta. Dentro desta perspectiva, não apenas as práticas corporais escolarizadas, como a "gymnastica”, eram tematizadas nas teses. Por exemplo, o Dr. Joaquim Pedro de Mello ${ }^{19}$ discutia inclusive temas marginais como a prostituição. Em seus termos: Eu deixo aos políticos, e aos moralistas a resolução deste problema pela parte, que lhes toca. Quanto ámim, que não procuro senão o bem physico geral, e particular, direi somente, e com muita confiança em minha opinião, que se se podesse fazer o parallelo, e supporem-se dous estados de igual numero de habitantes, da mesma idade, e sexo, e vivendo debaixo do mesmo clima, e governo etc. etc, differindo simplesmente, em que um tivesse mui poucas prostitutas, mas que soffresse uma peste de 5 em 5 annos, que ceifasse de cada vez a vigésima parte dos habitantes, comparando-se este com o outro, em que não se desse a peste, e sim um grande numero de lupanares, como se vêem nas cidades populosas, como Londres, Paris etc. etc, creio sem duvida, que no fim d'um século achar-se-hia o primeiro estado ainda mais povoado, e seos habitantes de constituição, e temperamento incomparavelmente mais vigorosos. [...] Se entende, que as mulheres publicas devem ser toleradas por motivos, que não nos cumpre discutir, deve-se ao menos tractar de impedir, que ellas illudao a innocencia, e que a arrastrem ao turbilhão do vicio; e para isto talvez fosse sufficiente o designarse um quarteirão retirado, d'onde não pudessem sahir sem certas precauções, e submettel-as á inspecçóes freqüentes, sequestrando-se aquellas, cuja saúde fosse duvidosa. Deste modo é provável, que se evitasse parte dos males horrorosos, que produzem a libertinagem, e a crápula (p.40-1).

Com isso evidenciamos que a "educação physica” constituía-se como uma educação moral sobre muitos aspectos. Por isso a diversidade de temas que permeavam o vocábulo. Outros médicos também utilizavam essa expressão como própria para a descrição da fisiologia humana, como o Dr. Antônio Nunes de Gouvêa Portugal ${ }^{20}$, em sua tese, "Influencia da educação physica do homem”, de 1853. Já para o Dr. João da Matta MaCHADO ${ }^{21}$, em sua tese "Da educação physica, intellectual e moral da mocidade do Rio de Janeiro: da sua influencia sobre a saúde", de 1874 , a "educação physica" poderia abranger a higiene de modo geral, e também a puericultura, alimentação, vestuário, em particular. Até mesmo os “temperamentos" das crianças eram alvo da "educação physica":

Sem constituir molestia, este temperamento é uma constante ameaça á saúde e á vida; felizmente, porém, é um facto incontestavel, a hygiene possue meios quasi seguros de aniquile sua funesta influencia, e até de operar a mais salutar metamorphose, transformando-o no temperamento sanguineo.

Destes meios os mais importantes são os que vamos enumerar, observando que cada um, considerado em separado, é insufficiente e ás vezes até perigoso, e que só do seu conjuncto, e da perseverança na applicação, se deve esperar resultados felizes. São os seguintes:

$1^{\circ}$. Residencia em lugar secco, alto e arejado. $2^{\circ}$. Exercicio muscular methodico (gymnastica), passeios ao ar livre, exposição directa aos raios do sol, nas horas de menos calor.

$3^{\circ}$. Alimentação reparadora sufficiente azotada. $4^{\mathrm{o}}$. Banhos frios, sobre tudo sob a forma de ducha (p.34) ${ }^{21}$. 
Estudo recente ${ }^{22}$ colocou a "educação physica" como estratégica na construção de um ideário médico e militar que sustentava um projeto de identidade nacional nos anos oitocentistas ${ }^{22}$. Particularmente, embora reconheça que o vocábulo era mais amplo do que é atualmente, ele constrói uma interpretação que enfatiza a relevância da ginástica no projeto de nação. Argumentamos, aqui, que os exercícios físicos representavam apenas uma dimensão limitada da expressão mais ampla "educação physica", que por sua vez, estava mais próxima do que identificamos hoje como higiene. A relevância da "gymnastica", desse modo, estava restrita, pois somente em conjunto com uma educação higiênica, que envolvia outros hábitos, poderia corroborar no projeto oitocentista de identidade nacional. Ao lermos as teses médicas do século XIX, temos que compreender que quando elas enalteciam a "educação physica", se referiam principalmente à higiene, e de forma secundária, à "gymnastica". Por exemplo, Dr. Joaquim Pedro de Mello ${ }^{19}$ quando escrevia sobre a nação, argumentava sobre os benefícios desta "educação physica". Em seus escritos:

Resignamo-nos, por tanto, com a sorte; e, namorado pela magnitude, e transcendente importância d'um objecto, que principalmente para o nosso abençoado Brasil, paiz nascente, e eivado de prejuízos, que herdou, é sobremaneira momentoso, escolhemos para assumpto de nossa these - a educação physica dos meninos, - não para o desenvolvermos, como merece, por que, conscio do que somos, não nos hallucina a vaidosa pretenção de esgrimirmos com galhardia nossas frágeis armas na arena, onde tem já debatido valentes, e amestrados campeiōes, e que offerece terreno vasto para muitos volumes; mas ao menos para exhibirmos, ao terminar de nossa carreira escholar, uma prova do, quanto anhelámos vêr fulgurar, e progredir a nossa pátria na senda de prosperidade, e civilisação, a que tem direito de aspirar, e á qual certa mente não attingirá, se incauta continuar caminho da negligencia, e da rotina em objecto de tão palpitante, e saliente utilidade (p.I).

Civilizar, já que era forte a representação de um Brasil atrasado, de população desassistida pelo Estado, e abandonada aos vícios. A única forma de superar o quadro de pauperização era a educação, que para os médicos, era mais ligada a aspectos utilitários e práticos. Enfim a "educação physica" era o projeto de reforma do homem brasileiro. Afirma o Dr. Joaquim Pedro de Mello ${ }^{19}$ :

Ninguém pôde negar a amarga, e dolorosa verdade, cujas provas à cada instante encontramos, de que vícios, e vícios condemnaveis, existem ainda profundamente arraigados no espirito dos Brasileiros no, que concerne a educação physica, e aos quaes, de comcumitancia com outras causas, sem temeridade se pôde attribuir a grande mortalidade das crianças recém-nascidas, que se effectua de certo tempo para cá no Rio de Janeiro, e o triste espectaculo, que por toda a parte nos offerece uma espantosa quantidade de infelizes, que, verdadeiros spectros ambulantes, arrastrão uma existência pesada, e contristão o coração daquelles, que sinceramente aspirão a prosperidade de seo paiz (p.VII).

Outro indício sobre o plano secundário da prática específica da "gymnastica" escolarizada nos escritos da medicina brasileira, já que se detinha mais efusivamente sobre seu projeto de higienizaçáo, era a ausência de diálogo com a literatura europeia sobre exercícios físicos. Nomes importantes da área na Europa, como Francisco Amoros (1770-1848), PerHenrick Ling (1776-1839), Friedrich Ludwig Janh (1778-1852) não são citados pelas teses médicas. Em vez disso, os clássicos gregos e o "Emílio" de JeanJacques Rousseau (1712-1778) eram os argumentos de autoridade mais utilizados. Exemplo disto esta na epígrafe da tese intitulada "Algumas consideraçóes sobre a educaçam physica" do Dr. Manoel Pereira da Silva Ubatuda ${ }^{23}$, de 1845 . Ele cita Platão: "A 'melhor educaçam não é aquella, que dá ao espirito e ao corpo toda a força, toda a belleza, e toda a perfeiçam, que elles podem adquirir?' Platấo. Si é possivel aperfeiçoar-se a especie humana é preciso buscar-se os meios na medicina" (p.1).

Contudo no contexto da higiene, traduzido em uma vigorosa "educação physica", o tema da escolarização da "gymnastica" também tinha espaço. Algumas teses, sobretudo a partir da segunda metade do século XIX, começam a analisar os exercícios físicos de forma mais específica, é o caso da tese do Dr. Carlos Antônio Pitombo ${ }^{24}$ intitulada "Apreciaçôes acerca dos exercicios physicos nos internatos e sua importância prophylactica”, defendida em 1900. Pois se os médicos elaboraram um projeto de nação saudável que envolvia diversos aspectos da sociedade, incluindo a educação formal, não teria sentido opor-se às práticas corporais institucionalizadas que ocorriam nas principais escolas da capital da Corte ${ }^{22}$.

Desse modo, o aprimoramento da saúde coletiva e individual elaborado com base em preceitos médicos e cientificistas incorpora-se à "gymnastica". $\mathrm{Na}$ tese do Dr. Carlos Antônio Piтомво ${ }^{24}$ fica evidente a legitimação dos exercícios físicos por parte dos médicos higienistas. Em seus termos "Obedecendo 
á sciencia, devemos fazer trabalhar regularmente todos os nossos orgãos para que não haja desequilibrio funccional, sendo indispensaveis para isso os exercicios physicos" (p.11).

As tentativas de consolidação da "gymnastica" ganharam força, portanto, a partir da inserção de um movimento, que viu nela, uma estratégia secundária, mas interessante para a imposição e instituição dos seus padrôes.

O Dr. Wilhelm NAEGeLI ${ }^{18}$, por exemplo, escreveu sobre os exercícios, situando-os de maneira particular no projeto higienista:

A utilidade dos exercicios gymnasticos está provada em nossos dias e a summa importancia delles na educação physica e na conservação da saude está reconhecida, bem como sua influencia moral e a eficacia therapeutica. Depois de pelejar quasi meio seculo contra as preoccupações e indifferença, ganhou a gymnastica a posição merecida tanto em relação á pedagogia, como á hygiene. Actualmente governos e povos esforçam-se para generalisar sua utilidade o mais possivel (p.3).

Outro aspecto relevante na análise deste documento está relacionado nas diferenças entre as classificaçóes europeias sobre os exercícios contidas nos clássicos da "gymnastica" de origem alemã, sueca e francesa com as descritas nas teses médicas brasileiras.

Para explicar esse distanciamento entre os textos europeus e as teses médicas brasileiras, além do plano secundário que os exercícios ocupavam no projeto higienista, temos que compreender que no país havia correntes médicas em confronto, pois enquanto um grupo identificava-se com a medicina experimental, com o laboratório, outro era muito ligado à retórica, e a discursos pomposos ${ }^{25}$. Os médicos que escreveram sobre "educação physica", "hygiene" e "gymnastica" nas teses do século XIX eram identificados com o segundo grupo. Seus escritos não citavam outros estudos contemporâneos, mas ao contrário, distanciavam-se da linguagem técnica com figuras de linguagem próprias da literatura. Um exemplo para esta interpretaçáo seria a tese do Dr. João da Matta MACHADO ${ }^{21}$ :

Neste capitulo discutiremos uma das questôes que mais interessam a educação physica, - o exercicio muscular. Nos tempos antigos os exercicios corporaes constituiam a base da educação da mocidade; ao contrario do que succede na actualidade, o desinvolvimento moral e intellectual era collocado em segundo lugar: ao Estado convinha mais possuir soldados aguerridos, habituados ás inteperies, ageis e vigororsos, do que sabios cacheticos ou jovens instruidos, porém debeis e effeminados (p.45).
A despeito do discurso moral do Dr. João da Matta $\mathrm{MACHADO}^{21}$ que revela a representação dos exercícios como prática identificada com o masculino e o belicismo, pretendemos vislumbrar sua distância em relaçáo à produção europeia sobre o tema no que diz respeito, por exemplo, sobre o papel da esgrima na "gymnastica" escolarizada.

Estudos $^{26-27}$ sobre a "gymnastica" escolar no Brasil oitocentista têm como fontes, principalmente, os planos de ensino de professores, que em sua maioria, têm relação com o militarismo e forte influência europeia. Nestas fontes, as aulas de "gymnastica", por exemplo, tinham presença marcante da esgri$\mathrm{ma}^{26-27}$. Contudo a descrição do Dr. João da Matta MACHADO $^{21}$ parece estar distante desta realidade. Nos seus termos:

Esgrima - o jogo das armas, tão generalisado nos paizes da velha Europa, no Brazil nunca teve acceitação, visto como o duelo felizmente não se coaduna com a nossa indole. Si debaixo deste ponto de vista nos devemos regozijar do desprezo que o povo brazileiro vota a esgrima, como hygienistas lastimamos que um exercicio tão conveniente e agradavel seja completamente banido dos habitos nacionaes. Os cursos de esgrima nos collegios de meninos seriam de grande vantagem; e este exercicio, ainda que fosse o único a que se entregasse os pensionistas, só por si satisfaria em grande parte as exigencias da hygiene do movimento. Por isso admiramo-nos que, sendo tão facil a sua creação nos estabelecimento de educação, sejam completamente olvidados (p.52-3).

A partir da ótica do Dr. João da Matta MACHADO ${ }^{21}$ sobre as escolas brasileiras, a esgrima sofria resistências, e era pouco influente, contrariando o que se sabe sobre "gymnastica" no Brasil. Podemos interpretar, entấo, que, ou a medicina estava distante da realidade das escolas, ou as interpretaçóes sobre o papel da esgrima nos colégios oitocentistas devem ser revistas.

Além disso, ainda sobre o cotidiano das aulas nas escolas, outras práticas consideradas complementares na organização das proposiçôes europeias sobre "gymnastica", como os jogos, têm destaque na descrição do Dr. João da Matta MACHADO ${ }^{21}$, que relata: "Os jogos da bolla, da corda, da peteca, usados geralmente em quase todos os collegios são de real utilidade, divertem singularmente os meninos e satisfazem as exigencias do systema muscular" (p.54). Para ele, o programa escolar teria como práticas a marcha, os saltos, a natação, a carreira. Sobre a última explica:

A carreira é uma combinação de marcha e do salto; exercicio energetico que rapidamente fadiga, deve 
ser reservado aos meninos e aos adultos vigorosos não muito pesados. Para os meninos a carreira é um exercicio summamente vantajoso ao qual elles se entregam levados por uma irresistivel inclinação. Alguns directores de estabelecimentos de educação prohibem rigorosamente as carreiras, receiando, dizem, as suas consequencias, e punem com impassivel severidade a infracção da regra: é que, em materia de educação, estes Herodes dos tempos modernos acreditam que o bom, que o justo, que o verdadeiro é contrariar todas as tendencias naturaes (p.51).

Mais uma vez, o Dr. João da Matta Machado ${ }^{21}$ ressalta a exclusividade de determinadas práticas aos meninos. Argumentando sobre sua natureza, construiu uma representação de desafio, coragem dos meninos que náo deveria ser reprimida pela escola.

Em relação à "gymnastica" no que tange à sua classificação, o Dr. João da Matta MACHADO ${ }^{21}$ distanciase, por exemplo, dos escritos de Amoros ${ }^{28}$ sobre os exercícios. Essa diferenciação reside na posição que a "gymnastica" ocupa no programa de escolarização. Pois para Amoros a "gymnastica" englobaria as outras práticas corporais condizentes com a ciência e a moralidade $^{28}$. Já para o Dr. João da Matta MACHADO ${ }^{21}$, ela seria apenas mais uma prática, isolada das outras. Porém essa diferenciação não é definitiva, pois existem aproximaçóes, por exemplo, na crítica do funambulismo encontrada nos escritos de Amóros ${ }^{28}$. O Dr. João da Matta MACHADO ${ }^{21}$ critica:

Gymnastica, segundo define Bailly, é a arte de regular os movimentos do corpo de um modo conveniente ao desinvolvimento das forças, da agilidade, da destreza, á conservação e restabelecimento da saúde e ao desinvolvimento das faculdades physicas e intellectuaes.

É evidente que a afirmação de Bailly só abrange a gymnastica racional, hygienica ou therapeutica, baseada sobre dados physiologicos, e não essa gymnastica de saltimbanco, perigosa e immoral, que consiste em saltos mortaes, equilibrios contra a natureza, capazes de deteriorar em pouco tempo a mais robusta constituição; e de fazer parar o desinvolvimento das crianças mais bem dispostas, tantas vezes victimas da sordida cubiça, que as sacrifica impiedosamente arruinando-lhe a saúde, assassinando-as lentamente para se servirem dellas como seguro meio de explorar a barbara, porem, eterna puerilidade humana (p.54).

$\mathrm{Na}$ constituição da "gymnastica", são comuns, tanto no Brasil quanto na Europa os argumentos contra os exageros $^{29-30}$. O Dr. Wilhelm NAEgELI ${ }^{18}$ ao argumentar sobre os benefícios dos exercícios, também alerta sobre o controle dos movimentos, pois não seria de qualquer forma que eles deveriam ser incentivados. Nos seus escritos:

Uma cousa é necessaria, isto é, que o organismo seja formado gradualmente para estes fins. Sempre a actividade deve ser em proporção à força productiva, por isso ha de se modificar segundo a idade, sexo, estado das forças, clima e costumes; e no caso de alguma disposição doentia, unma conservação particular ainda é precisa. A melhor norma para a quantidade da actividade muscular que se póde supportar, é a sensação do cansaço, que mostra-nos claramente que aquelle equilibrio está perturbado, que uma actividade mais crescida podia ser nociva e que por isso é necessario remove-la ou cessa-la (p.13-4).

GONDRA $^{14}$ explica que no pensamento dos médicos sobre os exercícios, o excesso é prejudicial ao desenvolvimento dos meninos, contudo a ausência deles também não é menos contraindicada. Em relação à educação, as práticas corporais também eram vistas por este ponto de vista, pois os médicos defendiam que o processo educativo deveria ser guiado pelo princípio da moderação e da vigilância permanente. Ressalta o Dr. Joaquim Pedro de Mello ${ }^{19}$ :

Estes exercícios, que occupao todo o tempo da recreação dos meninos, tem igualmente uma utilidade de não pequena monta, e é, que, fatigandoos, os obrigão á buscar um somno reparador, e á se distrahirem de funestas inclinaçōes, e de vícios hediondos, que ordinariamente segarão, e se arraigão nos momentos da occiosidade. Não é de menor importância o regular-se o tempo, em que os meninos devem-se entregar aos exercícios, e pôl-os em relação com sua força, ou fraqueza. Os exercícios violentos e muito prolongados não convém ás pessoas fracas, e as mesmas robustas podem ser incommodadas, logo que excedão os limites da moderação. Ha um grande numero de exercícios, que se podem dar aos jovens, proporcionando-os á delicadeza, ou energia de sua constituição. Assim a marcha, o salto, a dansa, a carreira, a natação, a esgrima e os diversos jogos, em que se executão movimentos do corpo, e braço, como a malha, a bolla, podem ser empregados com vantagem. A equitação, e a lucta entrao igualmente no numero dos exercícios, que se podem practicar (p.35).

Portanto, para estes médicos, as práticas corporais sem controle eram maléficas e prejudiciais. Porém quando elas eram praticadas com moderaçáo, deveriam ser incentivadas e disseminadas para toda a população. 
Além deste aspecto, no campo educacional, a utilidade dos exercícios era destacada por ser um facilitador do raciocínio, já que o exercício descansaria a mente, conforme defende o Dr. Wilhelm NaEgeli ${ }^{18}$ :

A faculdade de pensar é favorecida segundo a experiencia pela tranquilidade. Por esta razão os exercícios gymnasticos são um descanso, quasi uma derivação daquellas o atras actividades da intelligencia. Explica-se assim o effeito salutar em algumas molestias psychologicas, que são acompanhadas de actividade exaltada na percepção ou na imaginação. Como a actividade da vontade é indispensavel para os exercicios gymnasticos, e como a força productiva de qualquer orgão se desenvolve mais por uma actividade frequente, a vontade deve necessariamente tambem tornar-se mais desenvolvida e vigorosa. A gymnastica é por consequencia um meio excellente para combater com successo a fraqueza da vontade que se manifesta pela irresolução e pela indolencia, e para augmentar-lhe a energia, e assim sua influencia moral não é de pouca importancia (p.6).

A inculcação dos exercícios físicos como hábito higiênico, antes de ser a base de uma educação corporal, caracterizava-se também como uma educação moral. Ou seja, tinha a prerrogativa de reforma das atitudes. Valorizando, assim, a disposição, o trabalho físico era considerado um bem individual e coletivo, que deveria ser promovido desde a infância.

Para as crianças, por exemplo, o Dr. Carlos Antônio Рітомво ${ }^{24}$ defendia que a execução de exercícios equilibravam as funçôes orgânicas, proporcionando assim, uma maior resistência por parte dos alunos às doenças, já que:

A idade que decorre entre os sete annos e a plena

puberdade [...] está sujeita a um grande numero

de molestias e perturbaçōes organicas, que são

em grande parte favorecidas pelo proprio meio

escholar, podendo muitas vezes ser evitadas com

o uso dos exercicios physicos (p.25).

As adaptaçôes dos exercícios deviam ser orientadas pela faixa etária, mas também havia diferenciaçóes entre as atividades dos meninos e das meninas. No que concerne à "gymnastica" voltada para os corpos femininos, os médicos eram favoráveis a sua prática mediante algumas restriçôes ${ }^{31}$. Algumas atividades eram mais recomendadas ao gênero feminino, como por exemplo, danças ao ar livre, pois como afirma o Dr. Carlos Antônio Рітомво 24

As meninas têm menor tendencia aos movimentos do que os meninos; e esta differença se vae acentuando com o augmento da edade, tende a menina, e melhor a moça, prazer em divertimentos mais calmos, proprios do seu sexo. Ellas precisam de exercicios physicos mais moderados, de accordo com a sua organisação, que não supporta os esforços proprios aos meninos e rapazes (p.36).

Os exercícios físicos eram aplicados de modo variado para os diferentes gêneros, tendo por base a ideia de que o homem era mais "preparado" para o exercício militar, já as indicaçôes para meninas e moças, visavam uma formação moral e física voltada para a maternidade.

Ainda sobre o âmbito escolar, mais especificamente nos internatos, havia uma discussão sobre o ensino da "gymnastica". O Dr. Carlos Antônio Рітомво ${ }^{24}$, também se distanciando dos textos europeus, por exemplo, não vê a necessidade de uma "gymnastica" sistematizada, com a inclusão de aparelhos e, muito menos que seja exigido grande esforço da sua prática. Ele defende que devem ser utilizados "exercícios livres e racionalmente combinados e variados [...] e as liçóes se convertam para os alumnos em verdadeiros divertimentos e recreio" (p.36).

O recreio, momento de realização dos exercícios físicos era, decerto, reconhecido e valorizado como um privilégio, a tal ponto que, ao referir-se aos castigos aplicados nos colégios internos, havia a privação dos exercícios como uma medida disciplinar. Podemos dizer que tais medidas tinham fins, do ponto de vista médico, higiênicos e disciplinadores, levando em consideraçáo o desuso de uma atividade prazerosa, buscando razóes na construção de um corpo educado e disciplinado ${ }^{32}$.

O Dr. Carlos Antônio Piтомво ${ }^{24}$ mostra ainda, a necessidade da presença de um professor de "gymnastica" nas horas de recreio dos alunos para que estes possam indicar o melhor exercício a ser praticado, assim como a melhor maneira de praticá-lo.

Quanto à organização desses exercícios no ambiente escolar, os médicos procuraram definir uma pauta onde era possível identificar sete temas em torno dos quais o discurso era articulado: o diagnóstico das práticas corporais, os objetivos da educação do corpo, o lugar de educar, os agentes da educação física, o modo de educar, as atividades e os princípios que deveriam regê-las ${ }^{32}$.

Assim, o discurso médico da época defendia abertamente uma "gymnastica" escolar, com características higiênicas, sendo ela, disciplinadora, reguladora e disseminadora dos hábitos saudáveis. Defendiam, portanto uma prática moderada e principalmente acompanhada por um mestre capacitado com conhecimentos acerca dos conteúdos que regiam a "gymnastica".

A medicina e seus articuladores propuseram suprir as deficiências políticas dos dirigentes no campo educacional, ditando regras de formação do corpo 
sadio. O enquadramento disciplinar da criança teve seu horizonte nesta sociedade ordenada conforme as aspiraçóes dos médicos ${ }^{1}$.

Particularmente, a "gymnastica" escolarizada foi carregada de princípios higienistas que articulados com outras representaçóes formavam a gênese da Educação Física ${ }^{11}$. Ela se firmou neste contexto, onde era utilizada em conjunto com outras práticas na disseminação de hábitos higiênicos, mas também, na inculcação de uma mentalidade que representava o moderno, o urbano, o civilizado.

A mentalidade higienista colaborou para a lenta difusão dos exercícios físicos no contexto educacional do século XIX. Mas esta intervenção era ainda incipiente no século XIX para garantir sua disseminação no vasto território brasileiro, como aludiam os médicos. Havia imensas diferenças regionais entre o litoral e o interior, como preconizaram importantes higienistas e intelectuais do fim do século XIX e início do século XX.

Contudo os dados empíricos apresentados neste estudo reabrem a questão do papel dos médicos na institucionalização da Educação Física, pois vislumbram um distanciamento das teses médicas brasileiras em relação aos estudos europeus do século XIX sobre "gymnastica". Além disso, eles colocam em dúvida a influência da esgrima e dos jogos no cotidiano das aulas no contexto brasileiro. Revelam também diferenças entre o conceito de "educação physica" e "gymnastica", onde as teses que tratam do primeiro, dão um papel secundário ao segundo. Essa interpretação questiona a centralidade da "gymnastica" nas teses, pois ela representaria apenas uma estratégia em um conjunto diverso de práticas no âmbito da "hygiene".

Outro aspecto que deve ser pontuado é a compreensão dos ideais destes médicos movidos mecanicamente pelos interesses dominantes, já que seu projeto de nação, embora em bases patrióticas, era bastante crítico em relação à falta de intervenção governamental nos campos sociais, sobretudo, na educação. É interessante perceber que a credibilidade dos médicos sustentava sua institucionalização na educação formal como uma das estratégias para organizaçáo de uma nação ${ }^{33}$. Argumentos, por certo, muito antigos, mas que ainda hoje vigoram e são predominantes ${ }^{10}$.

\begin{abstract}
Medical discourse and Physical Education in schools (Brazil, 19th century)

In Medical thought, the reformation of society wasn't restricted in streets, avenues and buildings, in other words, wasn't enough the cities urbanization based in health precepts. It was necessary to reform the bodies too, which first occurred in the family, in children by the hygienic education. In this specific field of Hygiene that exercises became a focus of interest of Medicine. The objective of this study was to describe the context of the introduction of physical education in schools through the medical discourse of the 19th century. For this, it was realized a historical research that had as sources: the theses of the Faculties of Medicine of Rio de Janeiro and Bahia. It concludes that the mentality hygienist contributed to the slow diffusion of the exercises in the educational context of the 19th century. However the gymnastics, in specific, wasn't very important in the hygienist project.
\end{abstract}

KEY WORDS: History of medicine; Scholar physical education; Hygiene; Body.

\title{
Referências
}

1. Costa JF. Ordem médica e norma familiar. 2a ed. Rio de Janeiro: Graal; 1983.

2. Sevcenko N. A Revolta da vacina: mentes insanas em corpos rebeldes. Sáo Paulo: Cosac Naify; 2010.

3. Hochman G. A era do saneamento: as bases da política pública no Brasil. Rio de Janeiro: Hucitec; 1998.

4. Hochman G, Lima NT. Condenado pela raça, absolvido pela medicina: o Brasil descoberto pelo Movimento Sanitarista da Primeira república. In: Maio M, Santos R, organizadores. Raça, ciência e sociedade. Rio de Janeiro: Fiocruz; 1996. p.23-40.

5. Donzelot J. A polícia das famílias. Rio de Janeiro: Graal; 1980.

6. Universidade Federal do Rio de Janeiro. Faculdade de Medicina. Catálogo de teses da Faculdade de Medicina do Rio de Janeiro. Rio de Janeiro: FM-UFRJ; 1985.

7. Le Goff J. A história nova. 5a ed. São Paulo: Martins Fontes; 2005. 
8. Ariès P. A história das mentalidades. In: Le GoffJ, organizador. A história nova. 5a ed. São Paulo: Martins Fontes; 2005.p.207-36.

9. Mendes M, Nóbrega T. O Brazil-médico e as contribuições do pensamento médico-higienista para as bases científicas da educação física brasileira. Hist. cienc. saude-Manguinhos. 2008;15:209-19.

10. Paiva FSL. Contribuiçôes da hygiene à escolarização da educação física. Movimento (Porto Alegre). 2004;10:53-75.

11. Soares CL. Educação física, raízes européias e Brasil. 3a ed. Campinas: Autores Associados; 2004.

12. Silva M. A educaçáo física escolar/saúde: o discurso médico no século XIX. Rev Bras Cienc Esporte. 2004;25:97-112.

13. Gois Junior. E, Lovisolo HR. Descontinuidades e continuidades do movimento higienista no Brasil do século XX. Rev Bras Cienc Esporte. 2003;25:41-54.

14. Gondra J. Homo hygienicus: educação, higiene e a reinvenção do homem. Cad Cedes. 2003;23:25-38.

15. Lobo FCS. Apontamentos para o estudo da hygiene escholar. Salvador: Famed; 1895.

16. Gondra J. A sementeira do porvir: higiene e infância no século XIX. Educ Pesqui. 2000;26:99-117.

17. Patury JL. Hygiene escholar. Salvador: Famed; 1884.

18. Naegeli W. A utilidade dos exercicios gymnasticos nos paizes tropicaes. Rio de Janeiro: Typographia Perseverança; 1863.

19. Mello JP. Generalidades acerca da educação physica dos meninos. Rio de Janeiro: Typographia de Teixeira e Companhia; 1846.

20. Portugal ANG. Influência da educação physica do homem. Rio de Janeiro: Typ. Universal de Laemmert; 1853.

21. Machado JM. Da educação physica, intellectual e moral da mocidade do Rio de Janeiro da sua influencia sobre a saúde. Rio de Janeiro: Typ. de G. Leuzinger e Filhos; 1874.

22. Silva C, Melo VA. Fabricando o soldado, forjando o cidadão: o doutor Eduardo Augusto Pereira de Abreu, a Guerra do Paraguai e a educação física no Brasil. Hist. cienc. saude-Manguinhos. 2011;18:337-53.

23. Ubatuba MPS. Algumas consideraçóes sobre a educaçam physica. Niterói: Typografia EC dos Santos; 1845.

24. Pitombo CA. Apreciaçôes acerca dos exercícios físicos nos internatos e sua importância profilática. Salvador: Tip. Reis; 1900.

25. Sá DM. A ciência como profissão: médicos, bacharéis e cientistas no Brasil (1895-1935). Rio de Janeiro: FIOCRUZ; 2006.

26. Cunha Junior CF. Os exercícios gymnasticos no Collegio Imperial de Pedro Segundo (1841-1870). Rev Bras Ciênc Esporte. 2003;25:69-81.

27. Cunha Junior CF. Organização e cotidiano escolar da "Gymnastica" uma história no Imperial Collegio de Pedro Segundo. Perspectiva. 2004;22(N especial):163-95.

28. Amoros F. Nouveau Manuel d'éducation physique, gymnastique et morale. Paris: Tome premier; 1838.

29. Fraga AB, Goellner SV. Antinoüs e Sandwina: encontros e desencontros na educação dos corpos brasileiros. Movimento (Porto Alegre). 2003;9:59-82.

30. Soares CL, Madureira JR. Educaçáo física, linguagem e arte: possibilidade de um diálogo poético do corpo. Movimento (Porto Alegre). 2005;11:75-88.

31. Goellner SV, Votre, SJ, Pinheiro, MCB. 'Strong mothers make strong children': sports, eugenics and nationalism in Brazil at the beginning of the twentieth century. Sport Educ Soc. 2012;17:555-70.

32. Gondra J. Combater a "Poética Palidez": a questão da higienização dos corpos. Perspectiva. 2004;22:121-61.

33. Sant'anna DB. Higiene e higienismo entre o Império e a República. In: Del Priore M, Amantino M, organizadores. História do corpo no Brasil. São Paulo: UNESP; 2011. p.283-312.

\section{Agradecimentos}

Os autores agradecem o financiamento da pesquisa pela FAPERJ "Edital Apoio à Pesquisa na área de Humanidades", processo E-26/110.087/2012; e pelo CNPQ, “Edital Chamada Universal n.14”, processo 474099/2011-3.

ENDEREÇO

Edivaldo Góis Junior

Departamento de Educação Física e Humanidades

Faculdade de Educação Física

Universidade Estadual de Campinas

Av. Érico Veríssimo, 701 - Cidade Universitária

13083-851 - Campinas - SP - BRASIL e-mail: edivaldo@fef.unicamp.br
Recebido para publicação: 12/08/2013

1a. Revisão: 28/11/2013

2a. Revisão: 24/02/2014

Aceito: 24/02/2014 